\title{
O DISCURSO DAS MARCHINHAS CARNAVALESCAS E AS RELAÇÕES DE GÊNERO NO RIO DE JANEIRO (1930-1940)
}

\author{
The discourse of carnival musics and the gender relationships \\ in Rio de Janeiro (1930-1940)
}

Ronald Ericeira ${ }^{1}$

(Universidade Federal Rural do Rio de Janeiro- UFRRJ)

\begin{abstract}
The article weaves together gender studies and music carnival. We conceived the concept of gender as a social construction. We understood the composers of marches inserted carnival speech as a possibility to speak about gender relationships. Drawing on Bakhtin's reflections on language and society, we established a relationship between the context of Rio de Janeiro in the 1930 sand 1940 sand the social messages contained in the carnival musics. The results were commented through themes and semantic fields, which identified different views on women from Rio de Janeiro in compositions of Lamartine Babo, João de Barro and Ari Barroso, between 1930 and 1940.
\end{abstract}

Key-words: carnival music; gender; Rio de Janeiro; analysis of speech.

\section{RESUMO}

$O$ artigo entrelaça estudos de gênero e músicas de carnaval. Concebe-se conceito de gênero como uma construção agenciada no mundo social. Discute-se como os compositores de marchinhas carnavalescas utilizavam essa prática discursiva para abordar as relações de gênero. Recorrendo às reflexões de Bakhtin sobre linguagem e sociedade, estabelece-se uma relação entre o contexto do Rio de Janeirodos, anos 1930 e 1940, e as mensagens

1. Psicólogo, Mestre em Ciências Sociais pela UFMA e Doutor em Ciências Humanas (Antropologia Cultural) pela UFRJ e Doutor em Psicologia Social pela UERJ. Professor Adjunto do Departamento de Psicologia da UFRRJ. Seus principais interesses de pesquisa são: cultura popular, processos cognitivos, memória social e análise do discurso. 
sociais contidas nas marchinhas. Os resultados foram aprensentados por meio de categorias temáticas e campos semânticos, os quais identificaram nas composições de Lamartine Babo, João de Barro e Ari Barroso, diferentes visões sobre as mulheres cariocas no período histórico investigado.

Palavras-chave: músicas carnavalescas; gênero; Rio de Janeiro; análise do discurso.

\section{Introdução}

Em uma perspectiva sociológica, Matta (1994) assevera que as músicas de Carnaval ajudam a pensar o Brasil. Tais canções se difundem em todas as camadas sociais, transpondo fronteiras econômicas, etárias e sexuais, sendo, potanto, instrumentos simbólicos pelas quais a sociedade brasileira encontra meios para dramatizar seus valores sociais, para pensar suas relações de poder, bem como para aludir a questões referentes ao relacionamento entre homens e mulheres no país.

A despeito dessa relevância das músicas de Carnaval para desvelar fundamentos identitários de nosso país, seu estudo deixa a desejar com poucos trabalhos científicos publicados. Notadamente, o samba tem despertado maior interesse dos acadêmicos brasileiros com algumas teses e dissertações já escritas sobre o assunto. Por outro lado, as pesquisas sobre marchinhas são quase inexistentes. Assim, pareceume desafiante desvelar uma parcela dos sentidos sociais encobertos pelas marchinhas, particularmente as compostas entre 1930 e 1940.

A justificativa para este recorte temporal advém de diversos fatores. O primeiro calca-se no fato de este período de tempo ser apontado por pesquisadores como a fase dourada das marchinhas no Brasil (TINHORÃO, 1997; ALENCAR, 1979). Nas décadas subsequentes, o samba coloniza o país, tornando-se a música brasileira por excelência. Antes dessa colonização cultural exercida pelo samba, as marchinhas eram um dos principais veículos transmissores de mensagens sociais. Outra razão para a delimitação temporal desse objeto de investigação é de ordem metodológica. Levar a cabo uma pesquisa acadêmica tendo como parâmetro de investigação o período 
de 1930 e1940 foi mais exequível do que se pretender abarcar quase noventa anos de história das marchinhas no Brasil.

Nos primeiros levantamentos desta pesquisa três dados me chamaram a atenção: primeiro, a totalidade das canções era de autoria masculina; segundo, a maioria dos compositores pertencia às camadas médias cariocas; o terceiro aspecto, e talvez o mais relevante para os objetivos deste texto, refere-se ao fato de essas músicas apresentarem amiúde temas relacionados às mulheres. Nessa abordagem inicial, os temas identificados foram variados: a aparência física da mulher, assim como sua honra e seu comportamento sexual são exemplos.

Com efeito, procurei trazer à baila o modo pelo qual as mulheres foram representadas na obra de três compositores de marchinhas: Lamartine Babo, Ari Barroso e Braguinha. A delimitação da produção musical desses compositores deu-se por dois motivos específicos. Primeiramente, oriundos de realidades sócio-econômicas semelhantes, esses compositores puderam ser classificados como representantes dos segmentos médios cariocas dos anos de 1930 e 1940. Este aspecto econômico comum aos três facilitou a definição do lugar social de onde falavam a respeito do universo feminino. Segundo, os supracitados compositores são considerados pelos historiadores da música popular como os mais prolíferos produtores de marchinhas do país, sendo suas composições executadas até hoje nos dias de Momo.

Nessa perspectiva, meu objetivo foi refletir sobre os seguintes questionamentos: quais os sentidos atribuídos às mulheres nas letras de marchinhas no transcurso dos anos de 1930 e 1940? Como essas canções reproduziam as experiências de homens e mulheres no Rio de Janeiro naquele período?

\section{As marchinhas e o carnaval carioca}

Os historiadores do Carnaval carioca frisam que, até o fim do século XIX, não havia músicas específicas para o folguedo de Momo. Os grupos carnavalescos saiam pelas ruas cantando e dançando livremente maxixes, habaneras, modinhas, valsas e polcas. No ano de 
1899, porém, é composta a marcha-rancho Ó Abre-Alas. Esta foi a primeira música composta conscientemente para ser cantada durante o tríduo momesco, feita pela maestrina Chiquinha Gonzaga para o cordão carnavalesco Rosa de Ouro (DINIZ, 1999). Cabe observar que aquela canção foi composta especificamente para aquele grupo carnavalesco e não para o deleite da sociedade mais ampla. Somente na segunda década do século XX, as músicas de Carnaval passaram a ser produzidas em larga escala para serem cantadas pelo povo nas ruas e nos salões (ENEIDA, 1959).

A biografia escrita por Jairo Severiano sobre o compositor João de Barro - o Braguinha - revela que a marchinha seria um produto cultural das camadas médias urbanas cariocas. Elas teriam se consolidado como gênero musical na década de 1920. Nesse período, Freire Junior, José Francisco de Freitas e Eduardo Souto, músicos do teatro de revista da época, idealizaram um estilo de canção baseado em um ritmo alegre, em melodias simples e em letras curtas e jocosas (SEVERIANO, 1987, p.30).

Por sua vez, Alencar (1979) afirma que as marchinhas carnavalescas seriam oriundas de uma mistura musical entre a polca e duas danças norte-americanas - o one-step e o rag-time - difundidas no Rio de Janeiro entre 1910 e 1920. Ressalto que a primeira marchinha a fazer sucesso no Carnaval carioca foi Pé de Anjo, em 1920, de Sinhô. Com efeito, essa marchinha estava inserida dentro de uma peça teatral homônima. Aliás, foi o sucesso dessa peça que disseminou a marchinha junto ao grande público. Convém acrescentar que a popularização das marchinhas carnavalescas só foi possível, entre outros fatores históricos, pelos concursos de músicas populares que aconteciam na cidade do Rio de Janeiro desde 1919 (ERICEIRA, 2010).

Depois de 1931, a Prefeitura da cidade passou a organizar regularmente tais concursos, cujas canções participantes eram divulgadas nos meios de comunicação da época. A oficialização dos concursos e os incentivos financeiros oferecidos pela administração municipal aos vencedores acarretaram em uma ampla comercialização das músicas de Carnaval, emergindo, nesse transcurso, uma representativa parcela de intérpretes e compositores dessa canções, 
como Carmen Miranda, Mário Reis, João de Barro, Lamartine Babo, entre outros (SEVERIANO, 1987). Várias marchinhas, que até hoje são cantadas durante o reinado de Momo, surgiram nessa época. As mais conhecidas seriam: $O$ Teu cabelo não nega, de Lamartine Babo; Pierrô apaixonado, de Noel Rosa; A Mulata é a tal, de Braguinha.

Nesse ponto, destaco ainda os papeis exercidos pelo teatro de revista, pelo rádio e pelo cinema na divulgação das marchinhas carnavalescas. Programas de auditório, como Calouros em desfile, apresentado por Ari Barroso na Rádio Tupi e os filmes com temática momesca, como a $A \mathrm{Voz}$ do carnaval (1933); Alô, alô, Carnaval (1936) e Banana da terra (1939), foram importantes para que as marchinhas, malgrado expressassem o pensamento dos segmentos médios cariocas sobre os eventos cotidianos, passassem a gozar de aceitação em todas as camadas sociais.

Comentando e satirizando os comportamentos e os valores sociais, as marchinhas ajudaram a promover o Carnaval do Rio de Janeiro. Aliás, é uma marchinha - Cidade maravilhosa, de André Filho - a canção considerada o hino da então capital federal. Apesar de perder espaço social para os sambas-enredo a partir de 1950, as marchinhas ajudaram a escrever um importante capítulo da música popular brasileira.

\section{Mikhail Bakhtin e o discurso carnavalesco}

Neste estudo, priorizei as técnicas qualitativas e as teorias que concebem a imbricação inconteste entre linguagem e contexto social. No Brasil, os trabalhos acadêmicos voltados para a análise das mensagens sociais contidas em letras de músicas foram empreendidos, em sua maioria, por psicanalistas, antropólogos e historiadores. Cabe, então, um questionamento: com examinar as letras das marchinhas recorrendo a uma teoria dentro da análise do discurso? Entre os vários referenciais possíveis, decidi empregar como instrumental de pesquisa as reflexões de Mikhail Bakhtin (1986) sobre a linguagem.

Suas proposições teóricas ajudaram na condução de certos aspectos metodológicos deste estudo. No que tange à dimensão teórica, as conjecturas bakhtinianas contribuíram na dissolução de possíveis 
tensões relacionadas aos "talentos individuais dos compositores das marchinhas" e o contexto social vigente na época. Acreditar que a inspiração de suas obras se formou unicamente do seu psiquismo seria negar o caráter dialógico do pensamento humano.

Para Bakhtin (1986), a consciência individual é um fenômeno essencialmente social, pois, desde a sua origem, está submetida às leis dos sistemas ideológicos vigorantes. O centro organizador de todo pensamento e de toda linguagem não é interno, mas externo à consciência. Ele está situado nas teias sociais que envolvem o indivíduo, resultando na explicação do funcionamento do psiquismo humano por fatores exclusivamente sociais. Aliás, as enunciações individuais seriam produtos dos conteúdos circulantes na vida social. Os conteúdos ideológicos não se encontrariam na alma dos indivíduos, mas exteriorizados, em suas palavras, nos seus gestos, nas suas ações. Em outros termos, "todo conteúdo ideológico pode ser compreendido e psiquicamente assimilado, isto é, transmitido por intermédio de signos interiores" (BAKHTIN, 1986, p. 49).

Declarando a filiação teórica, cabe agora aprofundar como as premissas teóricas bakhitinianas contribuíram para a construção da análise aqui apresentada. Para Bakhtin (1986), o exame dos diferentes tipos de linguagem deve ser colocado em prática por meio de duas perspectivas analíticas. Primeira, do ponto de vista do conteúdo, dos temas que se encontram circulando no tecido social. Segunda, do ponto de vista das formas de discursos através dos quais esses temas são pensados e comentados socialmente. Acrescenta ainda que cada época tem seu repertório de tipos de discursos usado em sua comunicação ideológica (Cf, CASTRO, 2005, p.18).

Nessa perspectiva, a tarefa intelectualmente desafiadora é desvelar não apenas as formas linguísticas que entram em cena no ato da enunciação, mas captar os significados sociais atribuídos a determinados temas frente às condições de um dado momento histórico . Adotando essa premissa, realizei uma parcela dos procedimentos necessários para a investigação aqui pretendida, qual seja: o tema da pesquisa diz respeito aos significados sociais atribuídos às mulheres no Rio de Janeiro durante as décadas de 1930-1940. 
A segunda tarefa implicou na interpretação desses temas seus significados sociais - a partir da ótica das marchinhas. Nessa direção, considerei mister entendê-las como uma forma de discurso que a sociedade da época encontrou para comunicar seus valores e seus costumes. Na ótica bakhtiniana, a linguagem carnavalesca está associada à cultura cômico-popular, que se opõe aos tons formais das culturas religiosas e políticas oficiais. Tal linguagem seria dominada pelas paródias, ironias e risos. Bakhtin acrescenta que a linguagem carnavalesca constrói-se parodiando a vida cotidiana ordinária. Todavia, "é preciso assinalar que a paródia carnavalesca está muito distante da paródia moderna puramente negativa e formal; com efeito, mesmo negando, aquela ressuscita e renova ao mesmo tempo. A negação pura é alheia à cultura popular" (BAKHTIN, 1996, p. 10).

Baseando-me nos referenciais bakhtinianos, examinei as marchinhas como uma forma de discurso cujas enunciações estão abertas ao riso e às paródias festivas. Embora suas execuções e produções circulem principalmente ao período momesmo, seus temas podem variar dentro de um espectro de diversos assuntos, entre eles, o universo feminino. Do mesmo modo, os postulados de Bakhtin (1996) foram fundamentais também para organizar e interpretar o material coletado, bem como permitiram classificar os conteúdos das letras das marchinhas carnavalescas a partir de categorias temáticas.

\section{As letras das marchinhas carnavalescas: percurso analítico}

Como passo inicial, realizei o levantamento do repertório de marchinhas compostas por Ari Barroso, Lamartine Babo e Braguinha cujos núcleos temáticos se referiam às mulheres². Tratando-se de canções produzidas entre os anos de 1930 e 1940, muitas estão fora

2. Não diminuindo o talento musical dos supracitados compositores, pode-se entender suas composições como uma das formas jocosas que a sociedade carioca encontrou para comunicar suas percepções sobre as mulheres no Rio de Janeiro dos anos de 1930- 1940. 
de circulação comercial desde que as marchinhas perderam espaço para o samba junto às gravadoras de disco do Rio de Janeiro e de São Paulo ${ }^{3}$. Recentemente apenas as marchinhas mais conhecidas chegaram ao conhecimento do grande público, graças à reedição feita por artistas que, por sua vez, não estão ligados diretamente à divulgação de músicas carnavalescas, como a cantora Beth Carvalho. No que tange ao processo de análise das 43 músicas coletadas, identifiquei dois campos semânticos principais, bem como elaborei algumas categorias temáticas para nortear a interpretação qualitativa dos dados. Quanto aos campos semânticos, observei que dois temas se sobressaíam perante os demais: a definição da mulher por meio de algum aspecto físico ou natural, assim como as percepções das diferentes formas de relacionamento entre homens e mulhres.

No material coletado, é significativo o número de versos que nomeiam as mulheres pela tonalidade da pele ou pela etnia a que pertencem. A mulher era vista ou mencionada por um aspecto biológico. Por exemplo, a categoria cabelo foi empregada como uma espécie de metonímia das mulheres. Ademais, loiras, morenas e mulatas pareciam disputar a preferência estética de Lamartine Babo, de Ari Barroso e de Braguinha. Eis dois trechos:

1) Amei a mulatinha, amei a moreninha, em 32.. em 33.A loira namorei um mês. Agora eu fico com a melhor das três. Só porque o cabelo não negava, toda a gente só falava na mulata original...

(A Melhor das três, de Lamartine Babo)

2) O teu cabelo não nega mulata, porque és mulata na cor, mas como a cor não pega mulata, mulata, eu quero teu amor...

(O Teu cabelo não nega, de Lamartine Babo)

Poderia citar outros trechos em que a referência às mulheres acontece por meio da alusão à raça ou à tonalidade da cútis feminina.

3. A título de informação, coletei as letras das marchinhas carnavalescas nos arquivos do Museu da Imagem e do Som, bem como nas discografias existentes sobre os três compositores. 
No entanto, creio que as menções acima são suficientes para afirmar que tais canções não podem ser compreendidas fora da conjuntura cultural da época, pois, na década de 1930, o pensamento social brasileiro reformulava positivamente a visão sobre a mestiçagem nacional (FREIRE, 1981 [1933]). Outrora usada como explicação para o atraso intelectual e econômico do Brasil, a miscigenação passou a ser valorizada como elemento de alteridade da identidade brasileira.

Nesse contexto de valorização da mestiçagem como elemento definidor da identidade brasileira, os compositores aderiram a esse discurso social, elegendo a morena como a cor que melhor define a mulher nacional. A loira, apesar de uma possível beleza, era considerada como representante de terras estrangeiras. No entanto, ela poderia ficar com a cor nacional, caso viesse a habitar no país. Uma canção é exemplar na transmissão dessa mensagem:

3) Loura... Que vens de outra terra..., quero te dar o meu amor mais quente, do que o sol ardente deste meu país. Linda Loirinha, tens o olhar tão claro, deste azul tão raro, como um céu de anil, mas as tuas faces, vão ficar morenas, como as pequenas deste meu Brasil

(Linda loirinha, de Braguinha)

Outro conjunto de letras definindo as mulheres pela ótica biológica é concernente aos dotes e à beleza feminina. Nesse espectro semântico, são reiteradamente registrados os elogios a alguma parte do corpo das mulheres. Vejamos alguns versos:

4) Quando Mimi! Linda Mimi! Dos olhos que parecem pintadinhos de nanquim. Mimi! Não sei se eu vim num quadro de Xangai ou num Vaso de Pequim. E como seu tipinho, no Brasil não há...

(Linda Mimi, de Braguinha)

5) Ela bole com seus quadris, eu bato palmas e peço bis. Ai, mulata, cor de canela! Salve, salve, salve, salve, salve, ela!

(A Mulata é a tal, de Braguinha)

Além de assimilar a discussão em torno da mestiçagem em voga no país na década de 1930 , acredito que a profusão de citações aos 
aspectos físicos da mulher presentes nas letras das marchinhas reflete também o ponto de vista masculino que concebe a mulher enquanto um ser biológico, e não como um ser social dotado de capacidade intelectual ou de aptidão para o trabalho.

Seguindo também uma ótica biologizante, em várias composições a mulher é associada a objetos e a seres naturais. Nas letras dessas marchinhas, são recorrentes os usos de metáforas e de comparações entre a mulher e determinados elementos da natureza. Não foi raro encontrar citações por meio das quais a mulher-natureza é exaltada pela sua beleza física. Eis um exemplo:

6) Loiras, cor de laranjas cem mil. Salve! Salve! Meu carnaval, Brasil! Salve a loirinha dos olhos verdes, cor das nossas matas. Salve a mulata! Cor de café, a nossa grande produção! São! São! Quinhentas mil morenas. Loiras, cor de laranjas cem mil. Salve!

(Hino do carnaval brasileiro, de Lamartine Babo)

É oportuno esclarecer que esta última música referida foi gravada em 1939, em plena vigência do Estado Novo e da atuação do Departamento de Imprensa e Propaganda sobre as produções artísticas e culturais. Nesse transcurso, além da divulgação intensa dos feitos de Getúlio Vargas, os órgãos de imprensa e as instituições governamentais pregavam o patriotismo, exigindo a louvação deícones nacionais, entre eles o café e as florestas tropicais. Assim, não é surpreendente que os músicos tenham empregado, em suas produções artísticas, figuras retóricas para altear, ao mesmo tempo, a beleza física das mulheres e aspectos da natureza brasileira.

Nessa interpretação analítica do conteúdo dessas marchinhas, levei em consideração a dicotomia entre natureza e cultura, que é um tema caro às ciências sociais. Nas reflexões de Lévi-Strauss (2004), por exemplo, o estado da natureza está coligado ao instintivo, ao equipamento anatômico e à transmissão hereditária do material essencial para a sobrevivência do indivíduo e de sua espécie. Por outro lado, o estado de cultura supõe as regras sociais e as interdições, como o tabu do incesto que proíbe os casamentos endogâmicos. No entanto, 
sua referência principal para pensar as noções entre natureza e cultura dá-se pelas categorias de cru e de cozido (LEVI-STRAUSS, 2004).

O elemento cru seria a metáfora essencial da natureza, isto é, o alimento coletado em seu estado natural, sem passar por nenhum processo social prévio. Por seu turno, o cozido seria algo sóciocultural por definição, posto englobar as técnicas que cada grupo social desenvolveu para obter, selecionar e preparar o alimento (ERICEIRA, 2009). Trazendo essa reflexão para as letras das marchinhas, pode-se inferir uma visão da mulher associada à natureza e do homem à cultura ${ }^{4}$.

Das categorias temáticas criadas para fins de analisar o discurso das marchinhas coletadas para este trabalho, a mais frequente foi designada de mulher-dominante ${ }^{5}$. Essa categoria abrange todas as letras que, de algum modo, subvertem a ordem social androcêntrica que prevalecia no Rio de Janeiro no período histórico estudado. Em dez marchinhas examinadas, é a mulher que detém o domínio na relação. Contrariamente à dominação masculina que faz uso da agressividade e da gerência dos bens materiais para subjugar a mulher, esta recorre aos seus atributos físicos e à economia afetiva para exercer o controle sobre os sentimentos e comportamentos masculinos. Vale esclarecer que entendo por economia afetiva a quantidade de investimento que uma mulher deposita em uma relação amorosa a fim de que possa ter os homens sob sua égide. Nessa ótica, as formas de dominação feminina presentes nas marchinhas são polissêmicas. Examinemos alguns sentidos apreendidos no processo de interpretação de canções classificadas dentro do registro da mulher-dominante. Eis alguns exemplos:

7) Se eu fosse o teu coió, me transformava em pó pra arranhar teu sapato devagar. O meu prestígio já caiu no meu país natal. Não tenho nenhum cargo eleitoral. Se eu fosse presidente, mandava pra você o Tesouro Nacional...

(Dá cá o pé, loura, de Lamartine Babo)

4. Nesse aspecto, a divisão sexista inicial, em bases biológicas, entre homens e mulheres torna-se um aspecto da cultura carioca. Nessa classificação cultural, o homem está associado ao mundo social e a mulher à natureza.

5. Na pesquisa mais ampla, elaborei outras categorias temáticas para apresentar os resultados, entre elas: mulher-natureza, mulher-infatilizada, mulher-conflito, mulher-comida, mulher-dessexualizada. 
8) Mulata, por teu encanto, muito eu levei na cabeça. Porém, agora eu duvido que isso outra vez aconteça. Do teu falado feitiço, eu pouco caso lhe faço. Mandei fazei em São Paulo, mulata, um capacete de aço... Mulata, quando eu te vi, logo pedi anistia...

(Trem blindado, de Braguinha)

No fragmento (7), o eu (masculino) da marchinha emprega o termo coió, atualmente em desuso, para imaginar uma situação hipotética em que, sendo um namorado apaixonado, poderia cometer grandes tolices para conquistar a mulher, inclusive aceitando a condição subalterna de ser o pó do sapato dela. Nessa mesma marchinha, é notório ainda que o homem estava disposto a sacrificarse economicamente para agradar a mulher desejada.

No fragmento (8), inversamente ao trecho (7), o compositor não aventa mais situações imaginárias, dedicando-se a narrar eventos concretos do passado. Seguindo o fluxo discursivo proposto pela marchinha, salta à observação a descrição do sofrimento masculino por causa de uma mulata. Embora encontrando mecanismos para se proteger contra os seus feitiços, o homem sucumbe, pedindo anistia, perante o que denomina de olhar fuzilante da mulher. Notamos, pois, que o homem consegue resguardar-se dos poderes mágicos da mulata, mas se considera impotente ante a sedução do seu olhar.

Em outras composições, é mais clara a assimetria entre os gêneros, posto ser a mulher que exerce o controle da relação, fazendo com que o homem solicite seu amor e sua atenção. Alguns versos esclarecem o que quero dizer sobre esta temática:

9) Linda morena, morena, que me faz penar. A lua cheia que tanto brilha, não brilha tanto quanto o seu olhar... Teu coração é uma espécie de pensão, de pensão familiar à beira-mar. Oh, Moreninha, não alugues tudo não, deixe ao menos o porão para eu morar...

(Linda morena, Lamartine Babo)

No fragmento (9) acima destacado, é evidente que é o ser feminino o dirigente da economia afetiva do relacionamento, cabendo ao homem conformar-se com o que lhe for concedido pela mulher. 
O compositor confessa ser seu coração cativo de uma mulher. Nessa relação desigual entre senhora e escravo, é este que deve implorar a Deus que sua senhora se apiede, concedendo-lhe um beijo. Em outro conjunto de marchinhas, os compositores descrevem a amargura masculina, em razão de a mulher ter abandonado o homem logo após haver conquistado seu afeto. Eis algumas passagens:

10) A sorrir você me apareceu e as flores que você me deu. Guardei no cofre da recordação, porém depois você partiu pra muito longe e não voltou. E a saudade ficou, não quis abandonar meu coração. A minha vida se resume, oh, Dama das Camélias, em duas flores sem perfume.

(Dama das camélias, de Braguinha)

11) Segura esta mulher. Ela quer fugir. Roubou meu coração. Não pode escapulir, oi. Eu não sei o que vai ser! Meu amor, não sejas desmancha-prazer, oi.

(Segura esta mulher, de Ari Barroso)

No fragmento (10), o compositor empregou categorias psicológicas, como saudade, recordação e coração, para transmitirem a mensagem do desgosto masculino causado por uma mulher que o abandonou. Por sua vez, nos versos selecionados do fragmento (11), o compositor revela uma espécie de desespero do homem ao perceber que mulher amada pretendia abandoná-lo. Indicando a assimetria no relacionamento, o homem alça a mulher à condição de responsável pelo seu prazer ou desprazer. É oportuno salientar ainda que, em outro espectro semântico englobado pela unidade temática "mulherdominante", o homem se admite completamente consumido pelo amor que nutre pela mulher. $\mathrm{O}$ fragmento (12), a seguir, pertence a uma marchinha é bastante assertiva nesse sentido:

12) Ô Balancê, balancê, quero casar com você. Entra na roda, morena, pra ver. Ô balancê, balancê. Quando por mim, você passa, fingindo que não me vê, meu coração quase se despedaça. No balancê, 
balancê. Você foi minha cartilha, você foi meu $A B C$, e por isso eu sou a maior maravilha. No balancê, balancê. Eu levo a vida pensando, pensando só em você.

(Balancê, de Braguinha)

O fragmento (12) permite sugerir que a marchinha 'Balancê' marca, logo nos versos iniciais, a pretensão do homem de casar-se com a mulher. Ele sente seus sentimentos dilacerados quando a amada finge desprezá-lo. Sinalizando a inferioridade masculina, a canção enfatiza que a mulher ensinou todas as coisas da vida ao homem, por isso este leva a vida pensando nela.

Em outra marchinha, a atribuição tradicional dos qualificativos de gênero, representando o homem como o ser ativo e insaciável para o sexo e a mulher como passiva e fria na cama, é invertida. Na canção, é o homem que se vê alarmado com a ardência sexual feminina. Transcrevo a seguir os versos dessa marchinha:

13) Queimei-me todo outro dia. Eu não sei o que seria: se o sol do mar ou o sol que trazes dentro do teu olhar. A tua ardência me assombra. Tu tens quarenta graus à sombra. Desta maneira, só mesmo te botando numa geladeira...

(Moreninha da praia, de Braguinha)

É pertinente sinalizar ainda que tão-somente em uma canção dentre as analisadas é o homem quem decide insubordinar-se às designações femininas. Isso porque sua própria integridade física estaria em perigo, caso aceitasse realizar o desejo da mulher. Eis a forma como o compositor tratou carnavalescamente esta temática:

14) Eu fui às touradas em Madri. E quase não volto mais aqui pra ver Peri beijar Ceci. Eu conheci uma espanhola natural da Catalunha. Queria eu tocasse castanhola e pegasse touro à unha. Caramba, caracoles, sou do samba, não me amoles. Pro Brasil, eu vou fugir. Isso é conversa para boi dormir.

(Touradas em Madri, de Braguinha) 
Convém observar que os fundamentos da recusa do homem em satisfazer o pedido feminino encontraram esteio em elementos da então recém-construída identidade brasileira. Relembro que essa marchinha foi produzida em plena vigência do Estado Novo, período em que as manifestações populares foram valorizadas positivamente, sendo alavancadas ao patamar de ícones nacionais. Na canção em questão, os compositores acionaram o samba como índice de pertencimento à cultura brasileira, logo, não poderiam concretizar os pedidos da espanhola, pautados em costumes da Catalunha.

\section{Considerações finais}

A análise do discurso dessas marchinhas teve como fundo a cidade do Rio do Janeiro dos anos de 1930 e 1940. A então capital federal vivia a efervescência do cinema, do rádio e do teatro de revista. Por meio dessas manifestações artísticas as marchinhas popularizavamse junto ao grande público, ávido de divertimento e desejoso de conhecer seus artistas favoritos. Por outro lado, a vigência da ditadura getulista tolhia a livre expressão do pensamento, ao mesmo tempo em que estimulava as demonstrações de patriotismo.

Nesse cenário, onde se discutia a apropriação da cultura popular pelas instâncias governamentais e se valorizava as produções mestiças, as relações de gênero eram também um tema recorrente no cotidiano da cidade. Embora as mulheres tivessem obtido conquistas sociais, como o direito ao voto e à inserção em algumas atividades profissionais, a maioria dos discursos da época era conservador, assegurando direito de fala e de circulação nos espaços públicos preferencialmente aos homens. Historicamente, sabe-se que quem é autorizado a falar é investido de um poder advindo do lugar que ocupa na sociedade. Essa autorização é legitimada em função da posição social, da raça e do gênero daqueles que proferem os discursos hegemônicos. No período getulista, o sujeito imbuído do direito de falar era prioritariamente do segmento médio, branco e pertencente ao gênero masculino. 
Um dado relevante a ser mencionado sobre as músicas de Carnaval é que elas são polissêmicas, isto é, cada marchinha traz em seu bojo vários sentidos. Optei por delinear as visões que apareciam com maior frequência nas letras examinadas. Assim, um primeiro aspecto destacável é a negação da mulher como um ser social, ou seja, reiteradamente, ela foi representada por conteúdos biológicos ou naturais. É com essa compreensão cultural de ver o ser feminino por aspectos biológicos ou naturais que diversas marchinhas foram compostas $^{6}$. $\mathrm{Na}$ acepção dos compositores, a mulher ideal era apontada como bela, jovem, capaz de despertar o interesse sexual masculino, mas que, ao mesmo tempo, fosse submissa e fiel ao homem.

Nesse viés, as marchinhas serviam como espécie de veículo de comunicação por meio do qual os setores médios cariocas podiam fazer apelo às normas e às repreensões sociais para fins de manutenção da dominação masculina na sociedade carioca da época. A mulher que saía sozinha à noite desacompanhada ou que fizesse algo que desagradasse ao marido poderia ter duas punições: a difamação ou a agressão física.

Nem todas as visões concernentes às mulheres nas letras das canções investigadas apontam para uma assimetria em favor do masculino nas relações de gênero. Na maioria das marchinhas, o fato de a mulher exercer o controle da economia dos afetos na relação obrigava o homem a permanecer sob a sua égide. Nessas canções era o ser feminino quem decidia pelo começo, pela continuidade ou pelo fim do relacionamento. Em certa medida, a decisão feminina era a responsável pela alegria ou pelo sofrimento psicológico masculino. Notadamente, porém, essa visão da mulher ocupando o papel dominante na relação pautava-se em representações que atrelavam o universo feminino ao domínio dos afetos; em oposição, portanto, ao mundo do intelecto e do trabalho, que permaneceriam como prerrogativas masculinas (BOURDIEU, 1999).

6. Reitero que os compositores eram homens falando da mulher. Esta não tinha direito à fala própria. Nessa perspectiva, estávamos no mundo "falocrático" por excelência: a voz que construía e representava o feminino era a voz do masculino. 
Baseando-me no que foi exposto acima, é possível afirmar que, sob o ângulo dos compositores de marchinhas, não havia nem um único perfil feminino, nem um modelo padrão de relacionamentos entre homens e mulheres. As relações de gênero podiam acontecer sob a dominação masculina, quando o homem fazia uso de seu poder econômico, de sua força física ou dos costumes da época que apregoavam a submissão feminina. Por outro lado, a dominação feminina se consubstanciava quando a mulher recorria a seus dotes físicos, ao seu charme e ao seu poder de despertar o desejo sexual nos homens para tê-los, conforme a sua vontade.

Recebido em: julho de 2012

Aprovado em: setembro de 2012 ronaldericeira@yahoo.com.br

\section{Referências bibliográficas}

ALENCAR, Edgar. A história do carnaval carioca através da música. Rio de Janeiro: Francisco Alves, 1979.

BAKHTIN, Mikhail.Marxismoefilosofiadalinguagem.SãoPaulo:Hucitec, 1986. - A cultura popular na idade média e no renascimento: o contexto de

François Rabelais. São Paulo: Eusp; Brasília: Hucitec, 1996.

BOURDIEU, Pierre. A dominação masculina. São Paulo: Bertrand Brasil, 1999.

CABRAL, Sérgio. No tempo de Ari Barroso. Rio de Janeiro: Lumiar, 1991.

CASTRO, Alexandre C. Olhai os delírios no conto: análise dos temas psicológicos nos contos de Machado de Assis. 190 f. Tese (Doutorado em Psicologia Social) - Instituto de Psicologia, Universidade do Estado do Rio de Janeiro, Rio de Janeiro, 2005.

DINIZ, Edinha. Chiqunha Gonzaga: uma história de vida. Rio de Janeiro: Rosas dos Ventos, 1999.

ENEIDA. História do Carnaval Carioca. Rio de Janeiro: Civilização Brasileira, 1958. 
ERICEIRA, Ronald. A reconstrução do passado da Portela na rede mundial de computadores e nas rodas de samba. 208 f. Tese (Doutorado em Ciências Humanas) - Instituto de Filosofia e Ciências Sociais, Universidade Federal do Rio de Janeiro, Rio de Janeiro, 2009.

FREIRE, Gilberto. Casa-grande e senzala.. Rio de Janeiro: J. Olympio, 1981. LÉVI-STRAUSS, Claude. Totemismo hoje. Petrópolis: Vozes, 2004.

MATTA, Roberto da. Conta de Mentiroso: sete ensaios de Antropologia brasileira. Rio de Janeiro: Rocco, 1994.

SEVERIANO, Jairo. Yes, Nós temos Braguinha. Rio de Janeiro: Funarte; Instituto Nacional de Música, 1991.

TINHORÃO, José Ramos. Música popular: um tema em debate. São Paulo: Editora 34, 1997. 